\title{
Reply to: 'The role of ocean dynamics in king penguin range estimation'
}

\author{
Emiliano Trucchi ${ }^{1,2 \star}$, Robin Cristofari ${ }^{2,3,4}$ and Céline Le Bohec ${ }^{3,4,5}$
}

REPLYING TO A.J.S. Meijers et al. Nature Climate Change https://doi.org/10.1038/s41558-018-0388-2 (2019)

In their Comment, Meijers et al. argue that the $5^{\circ} \mathrm{C}$ sea surface isotherm, one of the parameters used in the model of Cristofari et al. to map, hindcast and forecast king penguin range, is not a good proxy to locate the species' foraging area. Using a different approach and the average of two 30-year windows (1976-2005 and 2071-2100), they suggest that the Antarctic circumpolar current core (ACCc) will make only regional shifts of $\sim 100 \mathrm{~km}$, but with significant uncertainty across an ensemble of 11 Coupled Model Intercomparison Project Phase 5 (CMIP5) models.

Our scope, however, was not to predict the position of the ACCc, but king penguins' breeding and foraging behaviour. Several studies ${ }^{1-3}$ demonstrated that sea surface temperature (SST) is an accurate predictor of the species' foraging range, and shortterm poleward shifts in the $5^{\circ} \mathrm{C}$ isotherm have clearly been linked to decreased breeding success in past decades ${ }^{4}$. King penguins forage where their prey (myctophid fish stock) can be predictably found within average diving depth $(200 \mathrm{~m})$. King penguins are thought to use SST as a proximal cue ${ }^{5}$. Thus, in the context of our study, the strong behavioural association between SST and the species' foraging range is clearly more relevant than actual water mass representation.

We note that Meijers et al. present the displacement of the ACCc as defined by Sen Gupta et al. ${ }^{6}$, and not of the polar front (PF) itself. To the best of our knowledge, there is no evidence that the ACCc is a valid indicator of the king penguins' foraging range that is as good as or better than SST. In addition, the data presented by Meijers et al. show that, within nearly all the king penguin's range (between $50^{\circ} \mathrm{W}$ and $130^{\circ} \mathrm{E}$ ), the ACCc is displaced polewards by $\sim 100 \mathrm{~km}$. As the relationship between $\mathrm{ACC}$ and king penguin foraging efficiency is currently unknown, we cannot conclude if it will be a negligible or a critical displacement for some of the colonies.

The link between the ACCc and king penguins' behaviour is probably more complex than argued by Meijers et al., and we claim that empirical data remain a strong and reliable source of information for understanding animal ecology ${ }^{2,4}$. In addition, the biological features of the systems, such as the critical time for foraging during the breeding season (February in our model), must always be integrated into the model. Other indicators of the frontal position ${ }^{7,8}$, as well as higher resolution climate models $\left(\mathrm{CM} 2.6^{9}\right)$, may also fit king penguins' foraging behaviour, and they must be tested in real-case biological scenarios.

As multidisciplinary collaborations are probably the only way to understand complex processes like global climate change, we warmly concur with Meijers et al. that developing models integrating physical oceanographic and biological features should provide better predictions of both physical and biological systems, an approach we also advocated ${ }^{10}$.

Received: 21 April 2018; Accepted: 12 December 2018; Published online: 28 January 2019

\section{References}

1. Bost, C. A. et al. Large-scale climatic anomalies affect marine predator foraging behaviour and demography. Nat. Commun. 6, 8220 (2015).

2. Scheffer, A. et al. Combined influence of meso-scale circulation and bathymetry on the foraging behaviour of a diving predator, the king penguin (Aptenodytes patagonicus). Prog. Oceanogr. 141, 1-16 (2016).

3. Pistorius, P. et al. At-sea distribution and habitat use in king penguins at sub-Antarctic Marion Island. Ecol. Evol. 7, 3894-3903 (2017).

4. Le Bohec, C. et al. King penguin population threatened by Southern Ocean warming. Proc. Natl Acad. Sci. USA 105, 2493-2497 (2008).

5. Scheffer, A., Trathan, P. N. \& Collins, M. Foraging behaviour of king penguins (Aptenodytes patagonicus) in relation to predictable mesoscale oceanographic features in the Polar Front Zone to the north of South Georgia. Prog. Oceanogr. 86, 232-245 (2010).

6. Sen Gupta, A. et al. Projected changes to the Southern Hemisphere ocean and sea ice in the IPCC AR4 climate models. J. Clim. 22, 3047-3078 (2009).

7. Dong, S. F., Sprintall, J. \& Gille, S. T. Location of the polar front from AMSR-E satellite sea surface temperature measurements. J. Phys. Oceanogr. 36, 2075-2089 (2006).

8. Freeman, N. \& Lovenduski, N. Mapping the antarctic polar front: weekly realizations from 2002 to 2014. Earth Syst. Sci. Data 8, 191-198 (2016).

9. Delworth, T. L. et al. Simulated climate and climate change in the GFDL CM2.5 high-resolution coupled climate model. J. Clim. 25, 2755-2781 (2012).

10. Cristofari, R. et al. Full circumpolar migration ensures evolutionary unity in the emperor penguin. Nat. Commun. 7, 11842 (2016).

\section{Acknowledgements}

The authors thank S. Gille for helpful advice.

\section{Competing interests}

The authors declare no competing interests.

\section{Additional information}

Reprints and permissions information is available at www.nature.com/reprints.

Correspondence and requests for materials should be addressed to E.T.

Publisher's note: Springer Nature remains neutral with regard to jurisdictional claims in published maps and institutional affiliations.

(c) The Author(s), under exclusive licence to Springer Nature Limited 2019

'Department of Life Sciences and Biotechnology, University of Ferrara, Ferrara, Italy. ${ }^{2}$ Centre for Ecological and Evolutionary Synthesis (CEES), Department of Biosciences, University of Oslo, Postboks, Blindern, Oslo, Norway. ${ }^{3}$ Université de Strasbourg, Centre National de la Recherche Scientifique (CNRS), Institut Pluridisciplinaire Hubert Curien (IPHC), Strasbourg, France. ${ }^{4}$ Département de Biologie Polaire, Centre Scientifique de Monaco (CSM), Monaco, Monaco. ${ }^{5}$ Laboratoire International Associé (LIA-647 BioSensib, CSM-CNRS-Unistra), Monaco, Monaco. *e-mail: trcmln@unife.it 